Supporting Information

\title{
Products and Mechanism of Secondary Organic Aerosol Formation from Reactions of $n$-Alkanes with OH Radicals in the Presence of NO$_{x}$
}

\author{
Yong Bin Lim and Paul J. Ziemann
}

This Supporting Information consists of seven pages, containing one table of SOA yields for the reactions of $\mathrm{C}_{8}-\mathrm{C}_{15} n$-alkanes with $\mathrm{OH}$ radicals in the presence of $\mathrm{NO}_{\mathrm{x}}$, one figure of example particle number and volume distributions from the tetradecane reaction with $\mathrm{OH}$ radicals in the presence of $\mathrm{NO}_{\mathrm{x}}$, one figure with standard electron ionization mass spectra from the Wiley Mass Spectral Database, and three figures of TPTD desoportion profiles from the pentadecane and decane reactions with $\mathrm{OH}$ radicals in the presence of $\mathrm{NO}_{\mathrm{x}}$. 
Table S1. SOA yields from reactions of alkanes with $\mathrm{OH}$ radicals in the presence of $\mathrm{NO}_{\mathrm{x}}$.

\begin{tabular}{cc} 
Alkane Carbon Number & SOA Yield (\%) \\
\cline { 2 - 2 } 8 & 0.5 \\
9 & 2.0 \\
10 & 3.2 \\
& 4.4 \\
11 & 5.9 \\
& 10.2 \\
12 & 19.8 \\
& 29.7 \\
13 & 49.4 \\
14 & 55.3 \\
& 49.7 \\
& 55.8
\end{tabular}



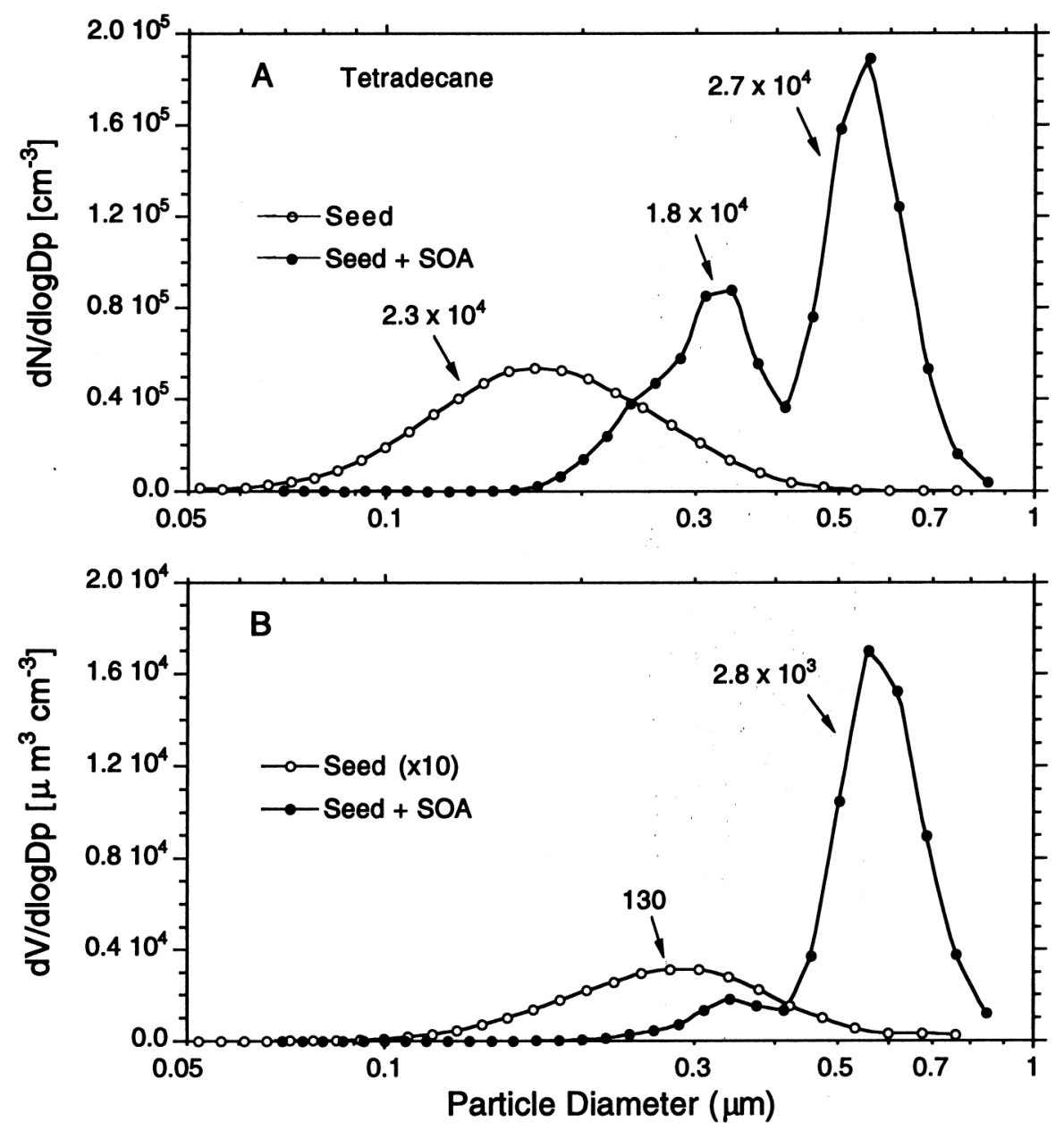

Figure S1. Particle (A) number and (B) volume distributions measured for DOS seed particles and DOS seed particles with SOA formed from the reaction of tetradecane with $\mathrm{OH}$ radicals in the presence of $\mathrm{NO}_{\mathrm{x}}$. The values associated with arrows correspond to particle number concentrations $\left(\mathrm{cm}^{-3}\right)$ and volume concentrations $\left(\mu \mathrm{m}^{3} \mathrm{~cm}^{-3}\right)$ in Figures A and B, respectively, for that particular mode. 

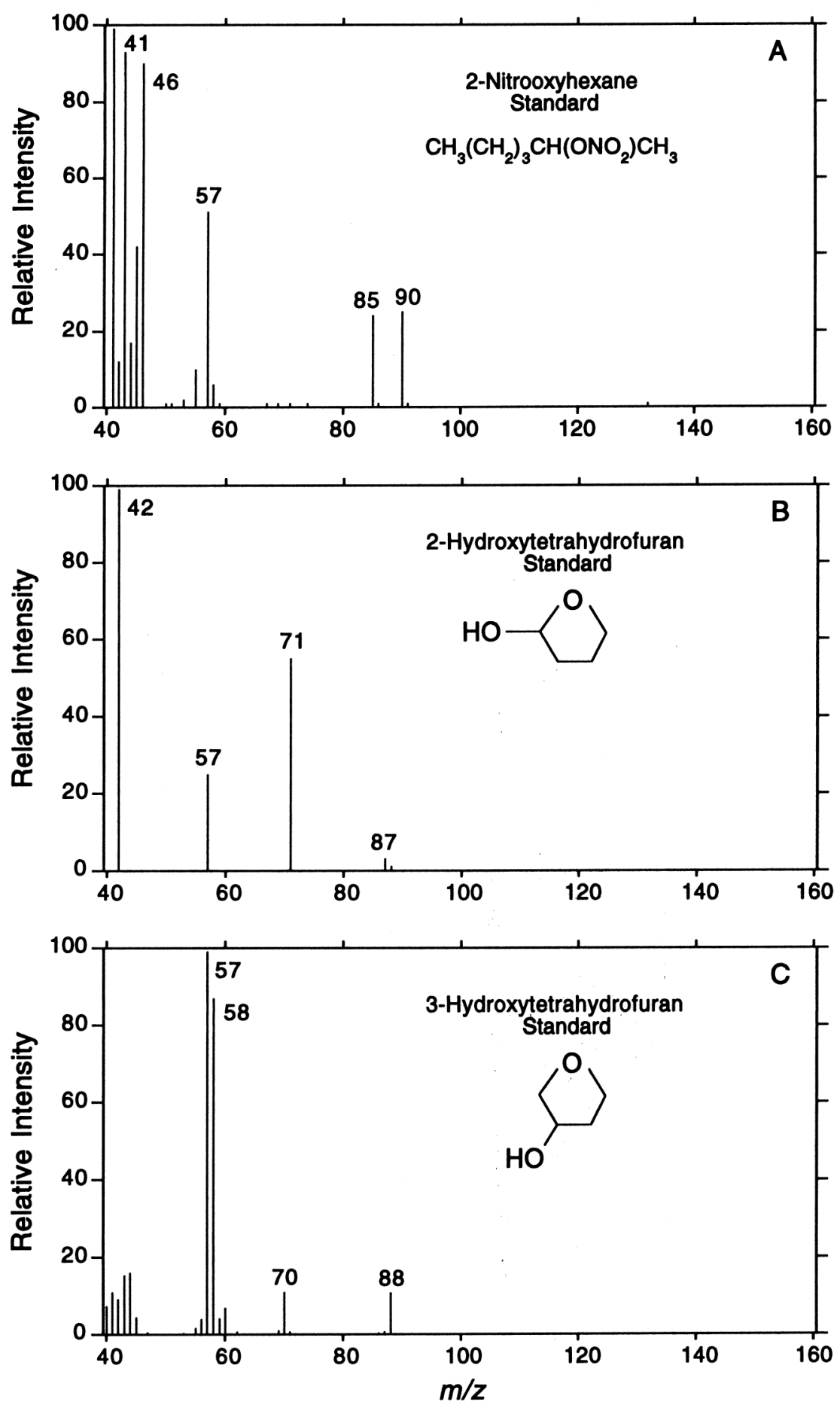

Figure S2. Electron ionization mass spectral standards: (A) 2-nitrooxyhexane, (B) 2hydroxytetrahydrofuran, and (C) 3-hydroxytetrahydrofuran. Figures were prepared using data from the Wiley Registry of Mass Spectral Data. 

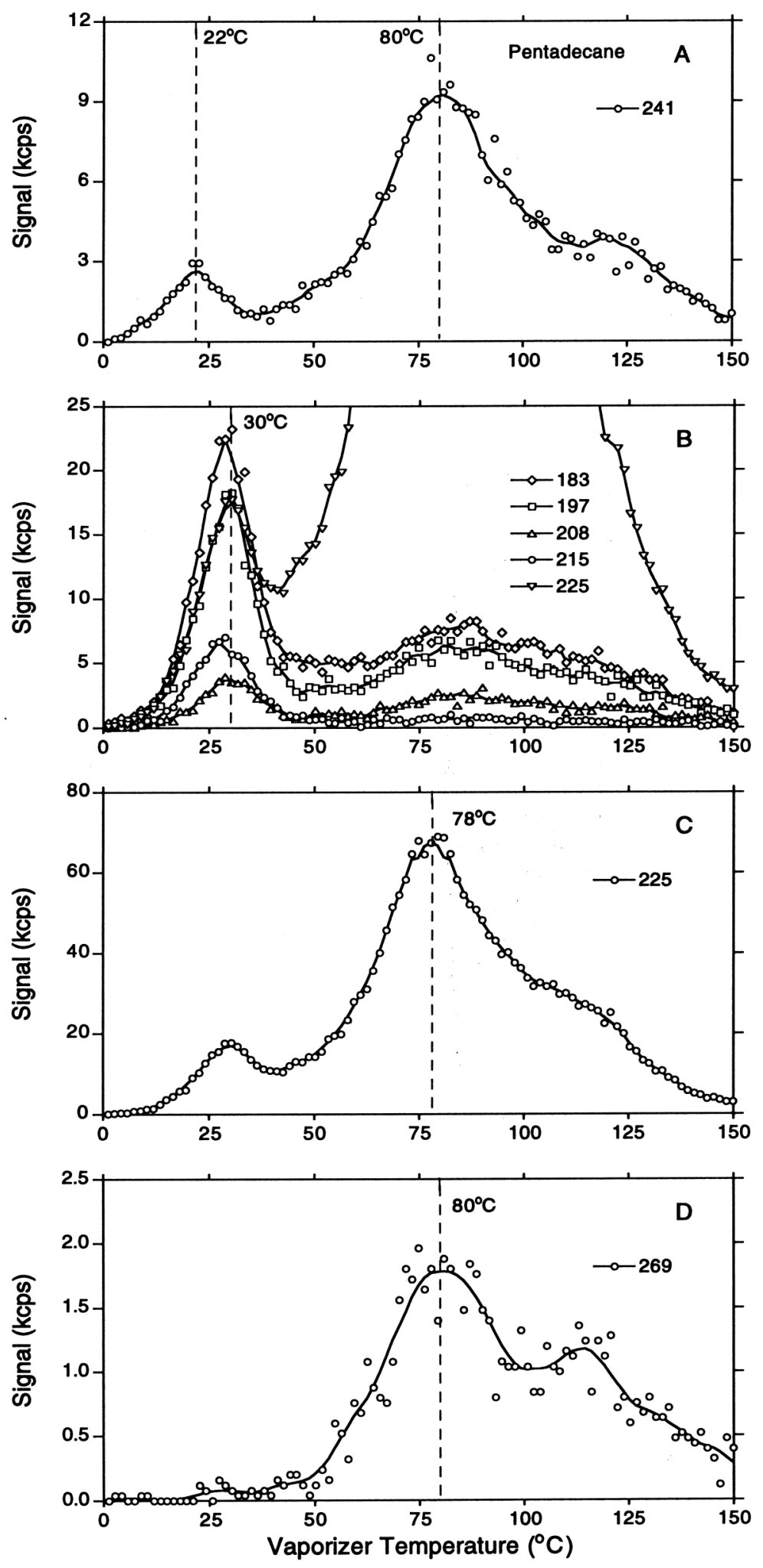

Figure S3. Thermal desorption profiles of $\mathrm{m} / \mathrm{z}$ values for SOA formed from the reaction of pentadecane with $\mathrm{OH}$ radicals in the presence of $\mathrm{NO}_{\mathrm{x}}$. 

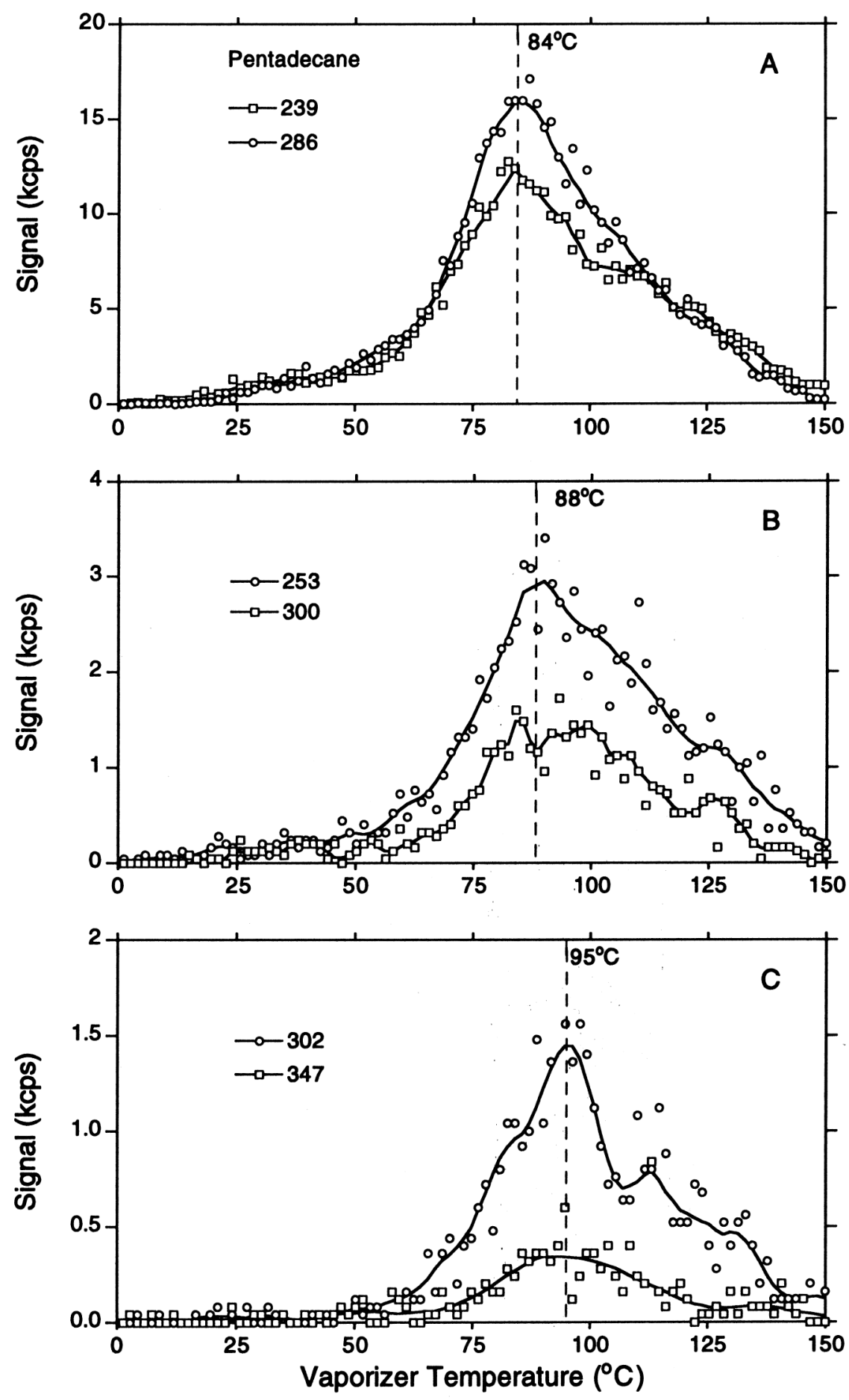

Figure S4. Thermal desorption profiles of $m / z$ values for SOA formed from the reaction of pentadecane with $\mathrm{OH}$ radicals in the presence of $\mathrm{NO}_{\mathrm{x}}$. 

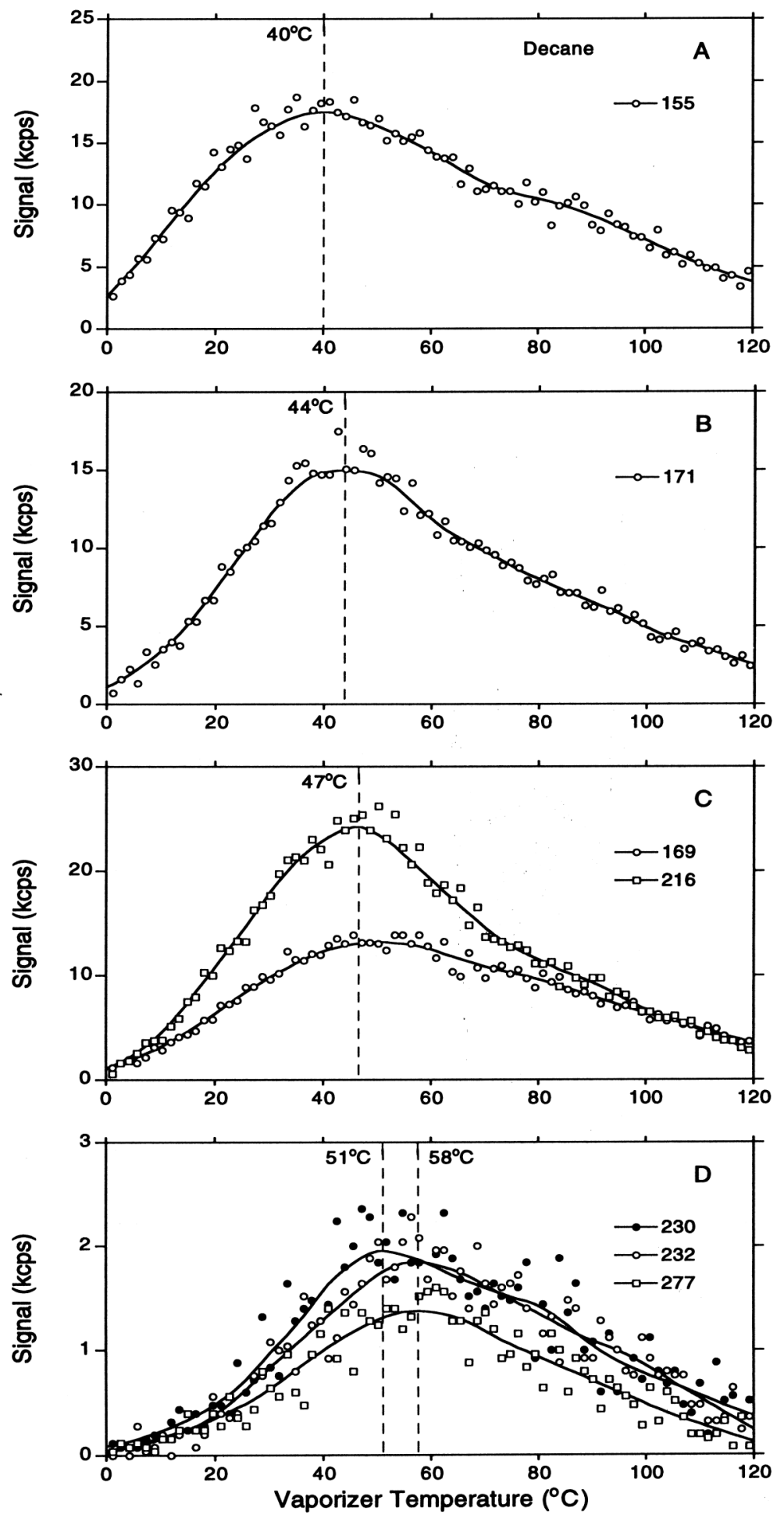

Figure S5. Thermal desorption profiles of $\mathrm{m} / \mathrm{z}$ values for SOA formed from the reaction of decane with $\mathrm{OH}$ radicals in the presence of $\mathrm{NO}_{\mathrm{x}}$. 